\title{
Parentification and Maternal HIV Infection: Beneficial Role or Pathological Burden?
}

Tanya L. Tompkins

Linfield College

Follow this and additional works at: https://digitalcommons.linfield.edu/psycfac_pubs

Part of the Maternal and Child Health Commons

\section{DigitalCommons@Linfield Citation}

Tompkins, Tanya L., "Parentification and Maternal HIV Infection: Beneficial Role or Pathological Burden?" (2007). Faculty Publications. Accepted Version. Submission 5.

https://digitalcommons.linfield.edu/psycfac_pubs/5

This Accepted Version is protected by copyright and/or related rights. It is brought to you for free via open access, courtesy of DigitalCommons@Linfield, with permission from the rights-holder(s). Your use of this Accepted Version must comply with the Terms of Use for material posted in DigitalCommons@Linfield, or with other stated terms (such as a Creative Commons license) indicated in the record and/or on the work itself. For more information, or if you have questions about permitted uses, please contact digitalcommons@linfield.edu. 
Parentification and Maternal HIV Infection: Beneficial Role or Pathological Burden?

\section{Tanya L. Tompkins}

Running head: Parentification and Maternal HIV/AIDS

Department of Psychology, Linfield College, 900 S.E. Baker Street, A570, McMinnville, OR 97128

e-mail: tatompki@linfield.edu 
Parentification, along with parenting and child adjustment were examined in 23 9-through 16-year-old youth from families affected by maternal HIV infection and 20 same-age peers whose mothers were not infected. Children whose mothers were HIV-positive reported to more often engage in parental role behaviors, relative to children of HIV-negative mothers. This difference remained even after controlling for the effects of current drug use, number of adults per child in the household, and marital status. Findings revealed a beneficial relationship between parentification and both child adjustment and parenting, particularly among families affected by maternal HIV infection. When relationships were examined separately by HIV status, the pattern of results suggested that parentification, which involves increased emotional closeness, rather than role-related tasks, which may involve increased responsibility of household maintenance, seems to foster an association with concurrent positive parenting and child adjustment among families coping with HIV/AIDS. Directions for future research, including the need for methodological advances in the field are discussed.

Keywords: parentification, HIV/AIDS, child adjustment, parenting, parental illness 
In families where a parent becomes ill or otherwise incapacitated, there may arise a role reversal in which the child assumes some or all of the instrumental and expressive caretaking functions for the parent (Barnett \& Parker, 1998; Chase, 1999; Mayseless, Bartholomew, Henderson, \& Trinke, 2004). This phenomenon, whether described in family system's (i.e. "parental child”) or relational (i.e., "parentification”) terms, has received little study to date (Broszormenyi-Nagy \& Spark, 1973; Minuchin, 1974). What is known is that, in families experiencing various stressors (e.g., single parenting, substance dependence, marital dysfunction, divorce, illnesses, imprisonment), the likelihood of parentification is increased (e.g., Godsall, Jurkovic, Emshoff, Anderson, \& Stanwyck, 2004; Goglia, Jurkovic, Burt \& Burge-Callaway, 1992; Sroufe \& Ward, 1980; Wallerstein, 1985). Factors unique to the HIV-affected family may heighten parentification risk. HIV involves complex and time-intensive medication regimens that prolong life, but also result in side effects that may disrupt role functioning. Furthermore, stigma and secrecy associated with HIV may decrease available social support and assistance with caretaking, making it more likely that children will be called upon to fill such roles. Finally, role reversals are relatively more common in drug abusing families and substance abuse may often precede or accompany HIV infection.

While Broszormenyi-Nagy and Spark's (1973) theoretical concept of parentification considers child caregiving to be a normative component of familial relationships, current research typically conceptualizes parentification as predominately pathological in nature. Although abdicating caretaking responsibilities to children can contribute to family dysfunction (i.e., boundary disturbances, future pathological 
caretaking, transgenerational cycle of dysfunctional parenting) and child psychosocial maladjustment (e.g., loss of childhood, neglect of developmental tasks such as identity formation, school achievement, attaining autonomous functioning), it may, in certain circumstances, lead to positive outcomes (e.g., increased self-esteem, greater sense of altruism, improved ability to take responsibility, increased sense of competence, enhanced coping, ability to nurture others), and is normative in certain cultures (Groce, 1995; Jurkovic, 1997; Jurkovic, Thirkield, \& Morrell, 2001). Several researchers in the field have discussed the need for construct refinement to include important contextual factors (e.g., developmental level; extent and duration of caregiving; support, acknowledgement, and reciprocity) and for the adoption of a risk/resilience framework to guide the exploration of factors associated with adaptive vs. destructive forms of parentification (e.g., Barnett \& Parker, 1998; Earley \& Cushway, 2002; Jurkovic et al., 2001). Questions regarding the degree to which children are placed in the caregiver role and whether the parentification by an ill mother (particularly due to HIV) is pathological or beneficial have been relatively disregarded. The absence of research on this topic seems neglectful, given the high concentration of risk factors present in these families and the evidence suggesting that many HIV positive mothers view their children as an important source of support (Andrews et al., 1993).

One notable exception, conducted by Stein and collaborators, found an association between more AIDS-related symptoms, more maladaptive aspects of parentified behavior (i.e., spousal and parental caretaking), and increased adolescent problem behaviors (Stein, Riedel, \& Rotheram-Borus, 1999). It seems reasonable to infer 
that parentification will also be seen in families coping with HIV infection, although its nature and extent are as yet unstudied. The current investigation addressed this lack of knowledge regarding the process and correlates of parentification in the context of maternal HIV infection. A particular strength was the inclusion of a control group that allowed for an examination of whether HIV infection, in the presence of other risk factors, uniquely predicts increased caregiving.

Higher rates of parentification were expected in those families affected by maternal HIV infection. This difference was hypothesized to emerge even after controlling for potential confounding factors such as maternal drug use, marital status, and number of children in the home. Additionally, in light of recent results demonstrating increased emotional support from childhood to early adulthood and consonant with normative developmental expectations and family life-cycle changes, parentification was expected to be positively associated with age such that older youth would report higher rates of parentification, regardless of group membership (Jurkovic et al., 2001). Although no specific hypotheses were offered, given the scarcity of empirical work in the area, the relationships between parentification, child adjustment, and parenting were explored.

\section{METHOD}

\section{Participants}

Participants in this study were 23 HIV-infected women and one of their non-

infected 9- to 16-year-old children and $20 \mathrm{HIV}$-seronegative women and one of their 9- to 16-year-old children $(M=12.8$ years $)$. Attempts were made to recruit numbers of 
African-American, Hispanic, and Caucasian participants reflective of the larger U. S. population of HIV-infected women resulting in 18 African- American (42\%), 19 Latina (44\%), and 6 European American (14\%) women being assessed as a part of this study. All mothers had previously participated in the UCLA-Drew Women and Family Project (WFP; see Wyatt \& Chin, 1999).

\section{Procedure}

In both groups, mothers and children participated separately in comprehensive interview sessions where information was collected about demographics, illness (HIV group only), parentification, parent-child relationship quality, parenting practices, family routinization and child functioning.

\section{Measures}

\section{Demographic Variables}

Demographic information (e.g., age of mother, age of child, educational attainment, work information, drug abuse history, family structure, etc.) was obtained during the initial interview with both the mother and the child.

\section{Illness Severity}

For HIV-affected families, information regarding the mother's health status (e.g., date of diagnosis, most recent CD4 counts, most recent viral load levels, CDC staging status) was obtained through a medical chart review by medical personnel or directly from the WFP. Each HIV participant was placed into one of three severity groups based on information extracted from their medical charts: (1) HIV positive, asymptomatic; (2) HIV positive, symptomatic; (3) AIDS diagnosis. 


\section{Child Psychosocial Functioning}

A variety of measures gathered from youth, mothers, and teachers were used to determine adjustment across multiple domains of functioning. The youth (Youth SelfReport - YSR), parent (Child Behavior Checklist -CBCL), and teacher (Teacher Report Form - TRF) versions of the CBCL were used to assess child behavior problems (Achenbach, 1991). As a measure of child depressive symptoms, the Children's Depression Inventory was administered to child participants (CDI; Kovacs, 1980/1981). The Revised-Children's Manifest Anxiety Scale was used to assess self-reported anxietyrelated symptoms (R-CMAS; Reynolds \& Richmond, 1997). Finally, the Self-Perception Profile for Children and parallel mother and teacher rating scales provided information regarding child social and behavioral competence (SPPC; Harter, 1985). Reliability across the various measures and reporters were acceptable (alpha coefficients ranging from .70 to .89).

\section{Parenting}

Parentification was assessed through mothers' and children's reports of experiences fulfilling typical adult or parenting roles during administration of the Parentification Scale (PS; Mika, Bergner, \& Baum, 1987). Four subscales have been suggested including: non-specific adult role taking (e.g., doing dishes), performing in a parental role to the parent (e.g., parent seeking advice from a child on adult matters), performing in a parental role to siblings (e.g., deciding what to do when a sibling misbehaves even when a parent is present), and adopting a spousal role in relation to the parent (e.g., parent sharing adult secrets with a child). Acceptable reliability in the 
current sample was found for only three of the four scales (spousal role, parental role to siblings, non-specific adult role taking) across both mother and child ratings (alpha coefficients were .76 for spousal role for both mother and child, .95 and .86 for parental role to siblings, and .78 and .65 for non-specific adult responsibilities, respectively). In the current sample, both mother and child ratings of the parental role to parent scale was found to have inadequate reliability (.59 and .40 , respectively). After deleting three items which involved fathers (e.g., keeping the peace, being the go-between) or illness (e.g., taking care of mother when she is sick), both the mother and child scales had acceptable reliability (.69 and .71 , respectively).

Relationship quality was assessed by the short form of the Conflict Behavior Questionnaire, with higher scores reflecting poorer relationship quality (CBQ; Robin \& Foster, 1989). In order to capture the reciprocal nature of relationship quality, both mother and child were administered the measure. Both mother and child instruments yielded acceptable alpha coefficients in the current sample (.90 and .89 , respectively). After being converted to z scores, mother and child CBQ scores were moderately and positively related $(\mathrm{r}=.63, \mathrm{p}<.001)$. The two indices were averaged to form a composite score of relationship quality. However, given the findings of Pelton et al. (2001), all analyses involving relationship quality examined mother and child perceptions of the relationship separately, in addition to utilizing the combined index.

Parenting practices were also assessed from the perspective of both mother and child as participants completed the Alabama Parenting Questionnaire (APQ; Frick, 1991). The APQ yields scores on several subscales including: involvement (e.g., "You ask your 
child about his/her day"), positive parenting (e.g., "You compliment your child when he/she does something well"), poor monitoring (e.g., "Your child is at home without adult supervision”), discipline, (e.g., "You take away privileges or money from your child as a punishment"), inconsistent discipline (e.g, "The punishment you give your child depends on your mood"), and use of harsh discipline (e.g., "You slap your child when he/she has done something wrong"). Items are rated on a 5-point scale, ranging from 1 ("never") to 5 ("always"). Given low reliability in the current sample, both the discipline and harsh discipline scales were not examined in any of the analyses. The other three scales were found to have adequate reliability, with alpha coefficients ranging from .80 to .85 across scales and reporter.

The Family Routines Inventory was used to assess consistency and organization of family routines (FRI; Jenson, James, Boyce, \& Hartnett, 1983). Mothers rated the items on a 4-point scale, ranging from 1 ("never") to 3 (“daily"), with higher scores reflecting more consistent family routines. Reliability was found to be acceptable in the current sample (alpha $=.84)$.

\section{RESULTS}

Children whose mothers were HIV-positive reported to more often adopt a parental role $(M=7.14, S D=2.98)$ relative to children of HIV- negative mothers $(M=$ 5.28, $S D=3.15), F(1,41)=3.88, p<.05$. A significant main effect of HIV status remained, even after controlling for the effects of current drug use, number of adults per child in the household, and marital status, $F(1,41)=5.22, p<.05$. Between-group differences on other parentification subscales and for maternal report of parentification 
were not significant. Generally, children reported significantly higher rates of parenting siblings, $t(41)=-2.37, p<.05$; parenting parents, $t(41)=-5.39, p<.001$; and performing more adult responsibilities, $t(40)=-4.10, p<.001$, relative to their mothers' reports.

Given that so little is known about parentification, particularly among HIVaffected families, the construct was examined both as it relates to demographic and illness-related variables and to child psychosocial adjustment. No gender or ethnic differences were detected for any of the parentification variables. Unexpectedly, child age was unreliably associated with parentification and when significant relationships emerged they were in the unpredicted direction with mothers of younger children reporting more parenting of siblings and younger children reporting more non-specific adult responsibilities. No significant differences between the asymptomatic and symptomatic/AIDS groups were found in levels of reported parentified behaviors. Additionally, only one significant relationship emerged between illness-related and parentification variables, suggesting that mothers who reported that their children more frequently adopted a parental role were also evidencing better health as indicated by higher CD4 counts $(r=.45, p<.05)$.

Results of the correlational analyses are presented in Table I. Apart from a marginal relationship suggesting that an increasing engagement in the parental role was associated with teacher-reported internalizing difficulties, most of the relationships suggest an adaptive relationship between parentification and child functioning. Mothers' reports of children increasingly adopting the parental role were associated with lower 
rates of self-reported child depressive symptoms and higher rates of child-reported social competence. Additionally, higher child-reported rates of non-specific adult responsibilities were also associated with higher mother-reported levels of social competence.

\section{Insert Table I here}

In connection with parenting behaviors and the parent-child relationship, several of the parentification variables were associated with parenting in favorable ways. For example, children's reports of more frequently engaging in a spousal role were associated with mothers' reports of more positive parenting. However, it should be noted that more frequent spousal role engagement was also associated with higher rates of poor monitoring. Mothers' reports of children more often adopting a parental role were associated with mothers' reports of more parental involvement. Additionally, children's reports of more frequently engaging in a parental role were associated with higher levels of mother-reported positive parenting. Higher rates of mother-reported parenting of siblings by the target child were associated with a higher degree of family routinization, while higher rates of child-reported parenting of siblings were associated with lower rates of poor monitoring.

Given an interest in understanding if and how parentification may differentially relate to parenting and child adjustment variables across HIV status, correlational analyses were conducted separately for infected and non-infected women. Fisher ztransformations were used to examine whether there were between-group differences in the strength and/or direction of the relationships between parentification and child 
adjustment and parenting. Examining between-group differences revealed intriguing disparities (Table II) and a general pattern across groups suggesting that instrumental caregiving was more closely associated with child adjustment whereas emotional caregiving was more strongly related to parenting. For example, children's reports of more frequently engaging in the parental role were directly associated with mother's reports of both maternal involvement and positive parenting, but only for families affected by maternal HIV infection. Similarly, relationships between child-reported spousal role engagement and mother-reported positive parenting and family routinization were significantly stronger for the HIV-positive group than for the seronegative group.

Insert Table II here

The relationship between child-reported parenting of siblings and child-reported externalizing difficulties was in the opposite directions for the two groups, with a strong inverse relationship among children of the non-infected group, and a relatively weak and positive relationship between these two variables for children of HIV-infected mothers. Similar patterns were found between children's reports of non-specific adult responsibilities and externalizing problems, with performance of adult responsibilities being associated with higher levels of externalizing problems for HIV-affected children, and lower levels of externalizing difficulties among children not affected by maternal HIV.

\section{DISCUSSION}

This study was conducted to examine parentification among HIV-infected women and to compare rates and correlates between families affected by maternal HIV infection 
and control families. Children whose mothers were HIV-positive, relative to children of non-infected mothers, more often reported engaging in parental role behaviors, but no group differences were found for other types of parentification. The present findings, which represent the first research efforts examining this construct among this specific population, underscore recent suggestions to contextualize and move beyond the tendency to pathologize parentification (Barnett \& Parker, 1998; Earley \& Cushway, 2002; Godsall et al., 2004). In our sample, parentification apparently was not associated with maladaptive parenting or child outcomes, particularly among families affected by maternal HIV. Contrary to expectation and to previous research examining parentification in a sample of parents with AIDS, the current findings suggested a salutary relationship between parentification and child adjustment (Stein et al., 1999). Mothers who reported that their children engaged in more parental role behaviors had children who reported lower levels of depressive symptoms and higher social competence. Children who reported having more non-specific adult responsibilities also reported higher social competence. Given the cross-sectional and correlational nature of the current results, it is unclear whether more competent and less depressed children are more frequently called upon to perform adult duties or whether the performance of mature roles results in higher perceived competence within the social domain. Future research examining parentification and child adjustment both concurrently and longitudinally will be critical in understanding the directionality of this relationship. Results examining relationships between parenting and parentification variables similarly suggested that parentification was mostly associated with positive aspects of 
parenting. Children reporting more spousal role behaviors had mothers who reported more positive parenting; however, these children themselves reported higher levels of poor monitoring. Mother and child reports of more parental role behaviors on the part of the child were associated with mother reports of more involvement and routinization. More parenting of siblings was associated with lower levels of poor monitoring and the maintenance of more consistent family routines. While it was somewhat surprising that different aspects of parentification (i.e., spousal, parenting siblings) were dissimilarly related to poor monitoring, spousal role behaviors that reflect more emotional caregiving, as opposed to the parenting of siblings that reflects more instrumental caregiving, may lead youth to feel mature enough to obviate the need for parental monitoring (e.g., indicating that they do not respect curfew). Additionally, it is possible that instrumental caregiving is more often supported and acknowledged and hence, perceived as just or fair. Jurkovic et al. (2001) found that perceived fairness within the family context was critical in explaining destructive parentification processes. Future work should explicitly measure the justice structure of the family as an important moderator of the relationship between child caregiving and parenting and child outcomes.

Examining the relationships between parentification and both child adjustment and parenting separately for HIV-positive and negative groups revealed intriguing differences. Among the families affected by HIV infection, child reports of more parental role behaviors were associated with mother reports of more involvement and positive parenting. These relationships were not seen in the comparison families. Child reports of more spousal role engagement were associated with mother reports of more positive 
parenting and routinization, and mother reports of more spousal role engagement by their children were associated with child reports of more involvement, again only for the HIVpositive group. Returning to child adjustment, children of HIV-negative mothers who reported more parenting of siblings and more non-specific adult role taking also reported fewer externalizing problems. Comparable children of seropositive mothers, in contrast, gave higher reports of externalizing difficulties.

This pattern of results suggests that the type of parentification which involves increased closeness in relationship to the mother (i.e., child taking spousal or parental roles), rather than tasks which may involve increased responsibility in non-social aspects of household maintenance, seems to foster an association with concurrent positive parenting and child adjustment among families affected by HIV infection. This interpretation is consistent with theoretical models which view child caretaking as a short-term attempt to regulate security within a stressed family system (Byng-Hall, 2002; Davies, 2002). Proponents of this model suggest that while such strategies may be effective (i.e., decrease stress and enhance security) in the short-term, in the long-run they may place children at risk for maladaptive outcomes.

Without a longitudinal perspective, it is unknown whether current findings that suggest a favorable relationship, regardless of directionality, will remain positive or whether performance of adult roles over time will become burdensome or interfere with the achievement of long-term developmental goals. Because the current research design did not provide a clear indication of the direction of the relationships between parentification, child adjustment, and parenting, nor of the long-term impact of the 
adoption of adult roles, such work seems acutely needed. Given that others have found that performance of parental role behaviors was associated with later externalizing problems within a sample of adolescents whose parents had AIDS, it seems particularly important to conduct longitudinal research with mothers in varying stages of illness (Stein et al., 1999). Such research should incorporate measures sensitive to the assessment of age-appropriate developmental tasks, in addition to distress and/or behavioral difficulties. Given generally higher rates of child- vs. mother-reported adult role taking, children's perspectives of their own functioning and family processes should be actively sought and understood prior to initiating intervention.

Although severity of illness appeared generally unrelated to parentification, a positive relationship between CD4 counts and mother reports of child parental role behaviors may suggest that mothers are not relying solely or mainly on their children to perform adult roles when illness prevents them from handling those roles independently. Although at odds with data suggesting that greater parental illness symptoms in parents with AIDS was associated with more spousal and parental role taking (Stein et al., 1999), when considered in light of recent research suggesting that mothers with AIDS may provide drastically different reports of child adjustment in comparison to mothers who are HIV-positive and symptomatic or asymptomatic (Dorsey et al., 1999), it may be that diagnostic status differentially influences perceptions and/or family processes. Such discrepancies underscore the need to examine parentification in a larger sample of women at varying stages of the disease process over time. 
Our understanding of the complex process of parentification within families coping with maternal HIV infection is limited. While the current study replicated earlier findings of increased child caregiving within families experiencing a major stressor it suggested that child caregiving, particularly within the context of maternal HIV infection, is not necessarily associated with pathological outcomes, such as disrupted parenting or child maladjustment (e.g., Goglia et al., 1992; Jurkovic et al., 2001; Stein et al., 1999). Although several limitations of the current study should be noted, including a small sample size, cross-sectional methodology, and reliance on self-report measures, the study's numerous strengths (e.g., multiple reporters, inclusion of a control group, concurrent vs. retrospective reporting, measurement of negative and positive aspects of parenting and child outcome) highlight the need to examine family process variables within the sociocultural context in which they occur. Clearly, this preliminary study leaves many unanswered questions. For example, do parents induct children into a parentified role and/or do children assume caregiving as a means of managing stress and maintaining security? What child, parental, familial, and sociocultural variables mediate or moderate the relationship between family stress and parentification and between parentification and child outcome? To what degree does explicit support for children's performing parenting duties (e.g., acknowledgement, communication, negotiation) influence children's perceptions of equity and/or their short-term and long-term adjustment? Finally, is there specificity with regard to the type of family stress as it relates to child caregiving and child functioning? These and many other unanswered questions await future investigations that employ a variety of methodologies (e.g., 
longitudinal design, observational measures, statistical modeling, variable-based and person-based research strategies), recruit diverse samples, and include broad-based assessment of child, parenting, family, and sociocultural variables of interest. 


\section{ACKNOWLEDGMENTS}

Tanya L. Tompkins, Department of Psychology, University of California, Los Angeles (UCLA).

This research was supported in part by a seed grant from the Universitywide AIDS Foundation. We gratefully acknowledge Gail Wyatt for offering collaborative opportunities. We thank Marisabel Canedo, Tasha Emmerson, Mercedes Floresislas, Tanya Hilty, Jamie Manwaring, Jaime Paz, Nuri Reyes, and Jenna Shih for their innumerable contributions to the project. We extend our deepest appreciation to the families who so openly shared about their experiences with HIV infection.

Correspondence concerning this article should be addressed to Tanya L. Tompkins, who is now at the Department of Psychology, Linfield College, 900 SE Baker Street, A570, McMinnville, Oregon 97128. Electronic mail may be sent to tatompki@linfield.edu. 


\section{References}

Achenbach, T. M. (1991). Manual for the Child Behavior Checklist 4-18 and 1991 profile. Burlington, VT: University of Vermont Department of Psychiatry.

Andrews, S., William, A. B., \& Neil, K. (1993). The mother-child relationship in the HIV-1 positive family. Image: Journal of Nursing Scholarship, 25, 193-198.

Barnett, B., \& Parker, G. (1998). The parentified child: Early competence or childhood deprivation? Child Psychology and Psychiatry Review, 3, 146-155.

Broszormenyi-Nagy, I., \& Spark, G. M. (1973). Invisible loyalties: Reciprocity in intergenerational family therapy. Hagerstown, MD: Harper \& Row.

Byng-Hall, J. (2002). Relieving parentified children's burdens in families with insecure attachment patterns. Family Process, 41, 375-388.

Chase, N. D. (1999). Burdened children: Theory, research, and treatment of parentification. Thousand Oaks, CA: Sage.

Davies, P. T. (2002). Conceptual links between Byng-Hall's theory of parentification and the emotional security hypothesis.Family Process, 41, 551-555.

Dorsey, S., Forehand, R., Armistead, L. P., Morse, E., Morse, P., \& Stock, M. (1999). Mother knows best? Mother and child report of behavioral difficulties of children of HIV-infected mothers. Journal of Psychopathology and Behavioral Assessment, 2, 191-206.

Earley, L., \& Cushway, D. (2002). The parentified child. Clinical Psychology and Psychiatry, 7, 1359-1045.

Frick, P. J. (1991). The Alabama parenting questionnaire. Unpublished instrument. 
University of Alabama.

Godsall, R. E., Jurkovic, G. J., Emshoff, J., Anderson, L., \& Stanwyck, D. (2004). Why some kids do well in bad situations: Relation of parental alcohol misuse and parentification to children's self-concept. Substance Use \& Misuse, 39, 789-809.

Goglia, L. R., Jurkovic, G. J., Burt, A. M., \& Burge-Callaway, K. G. (1992).

Generational boundary distortions by adult children of alcoholics: Child-as-parent and child-as-mate. American Journal of Family Therapy, 20, 291-299.

Groce, N. E. (1995). Children and AIDS in a multicultural perspective. In S. Geballe, J. Gruendel, \& W. Andiman (Eds.), Forgotten children of the AIDS epidemic (pp. 95-106). New Haven, CT: Yale University Press.

Harter, S. (1985). Manual for the Self-Perception Profile for Children. Denver, CO: University of Denver.

Jensen, E. W., James, S. A., Boyce, W. T., \& Hartnett, S. A. (1983). The Family Routines Inventory: Development and validation. Social Science Medicine, 17, 201-211.

Jurkovic, G. J. (1997). Lost childhoods: The plight of the parentified child. New York, NY: Brunner/Mazel.

Jurkovic, G. J., Thirkield, A., \& Morrell (2001). Parentification of adult children of divorce: A multidimensional analysis. Journal of Youth and Adolescence, 30, $245-257$.

Kovacs, M. (1980/1981). Rating scales to assess depression in school-aged children. Acta Paedopsychiatricia, 46, 305-315.

Mayseless, O., Bartholomew, K., Henderson, A., \& Trinke, S. (2004). "I was more her 
mom than she was mine:" Role reversal in a community sample. Family Relations, 53, 78-86.

Mika, P., Bergner, R. M., \& Baum, M. C. (1987). The development of a scale for the assessment of parentfication. Family Therapy, 14, 229-235.

Minuchin, S. (1974). Families and family therapy. Cambridge, MA: Harvard University Press.

Pelton, J., Steele, R. G., Chance, M. W., Forehand, R., \& The Family Health Project Research Group. (2001). Discrepancy between mother and child perceptions of their relationship II: Consequences for children considered within the context of maternal physical illness. Journal of Family Violence, 16, 17-35.

Reynolds, C. R., \& Richmond, B. O. (1997). What I think and feel: A revised measure of the children's manifest anxiety. Journal of Abnormal Child Psychology, 25, $15-20$.

Robin, A. L., \& Foster, S. (1989). Negotiating parent-adolescent conflict. New York, NY: Guilford Press.

Sroufe, L. A., \& Ward, J. J. (1980). Seductive behaviors of mothers of toddlers: Occurrence, correlates, and families of origin. Child Development, 56, 12221229.

Stein, J. A., Riedel, M., \& Rotheram-Borus, M. J. (1999). Parentification and its impact on adolescent children of parents with AIDS. Family Process, 38, 193-208.

Wallerstein, J. S. (1985). The overburdened child: Some long-term consequences of divorce. Social Work, 30, 116-123. 
Wyatt, G. E., \& Chin, D. (1999). HIV \& ethnic minority women, families, and communities: An overview. Cultural Diversity and Ethnic Minority Psychology, $5,179-182$. 
Table I: Correlations Between Parentification, Parenting, and Child Psychosocial Adjustment

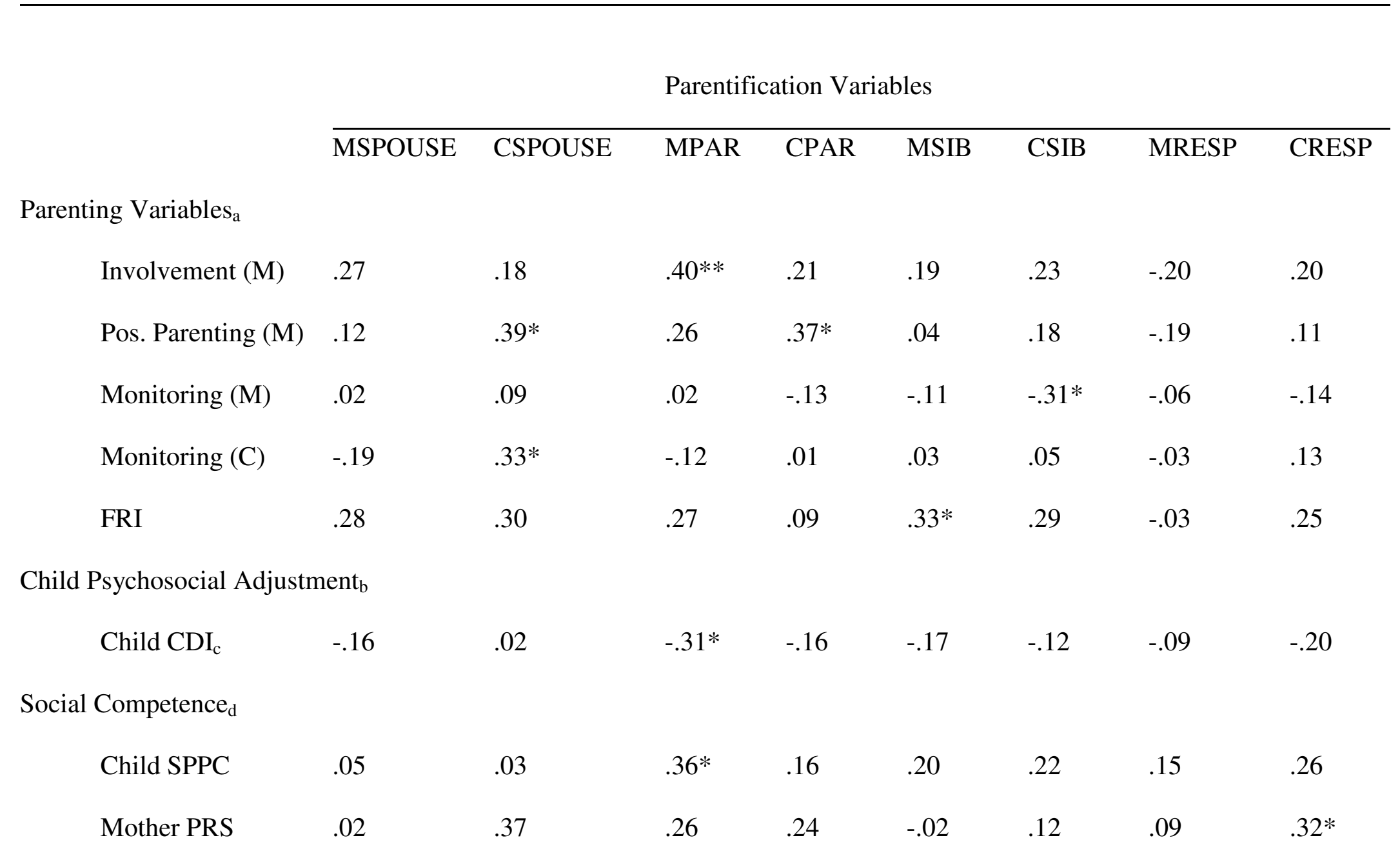


(Table I, continued)

Parentification Variables

MSPOUSE CSPOUSE MPAR CPAR MSIB CSIB MRESP CRESP

Note. MSPOUSE = Maternal report of Spousal Role(SR) subscale of the Parentification Scale (PS); CSPOUSE = Child report of SR subscale of the PS; MPAR = Maternal report of Parenting Role (PR) subscale of the PS; CPAR = Child report of PR subscale of the PS; MSIB = Maternal report of Parenting Siblings subscale of the PS; CSIB = Child report of Parenting Siblings subscale of the PS; MRESP = Maternal report of Non-specific Adult Responsibilities (AR) subscale of the PS; CRESP = Child report of Non-specific AR subscale of the PS; Involvement (M) = Mother report of involvement on Alabama Parenting Questionnaire (APQ); Pos. Parenting (M) $=$ Mother report of positive parenting on APQ; Monitoring $(\mathrm{M})=$ Mother report of poor monitoring on APQ; Monitoring $(\mathrm{C})=\mathrm{Child}$ report of poor monitoring on APQ; FRI = Mother report of family routines on Family Routines Inventory; CDI = Children's

Depression Inventory; SPPC = Self-Perception Profile for Children; PRS = Parent Rating Scale

${ }^{a}$ Only those parenting variables that were significantly associated with parentification are presented.

${ }^{\mathrm{b}}$ Externalizing difficulties were not associated with any of the parentification variables and are thus not presented. 
(Table I, continued)

${ }^{\mathrm{c}}$ Teacher-reported internalizing problems were marginally related to child-reported parental role behaviors, $\underline{\mathrm{r}}=.34, \underline{\mathrm{p}}=.06$.

${ }^{\mathrm{d}}$ Cognitive competence measures were not related to any of the parentification variables and are thus not presented. $* \mathrm{p}<.05 . \quad * * \mathrm{p}<.01$. 
Table II: Correlations Between Parentification Variables, Parenting, and Child Adjustment by HIV Status

\section{SPOUSAL PARENTAL SIBLING RESPONS.}

\begin{tabular}{lcccc}
\hline & \multicolumn{3}{c}{ HIV-Positive } \\
Maternal Involvement (APQ) & .40 & $.47_{\mathrm{a}}^{*}$ & .26 & .28 \\
Positive Parenting & $.63_{\mathrm{b}}^{* *}$ & $.55_{\mathrm{c}}^{* *}$ & .28 & .29 \\
Family Routinization & $.60_{\mathrm{d}}^{* *}$ & .28 & .30 & .19 \\
YSR-Externalizing & .16 & .16 & $.27_{\mathrm{e}}$ & $.35_{\mathrm{f}}$ \\
& & & & \\
\hline & & HIV-Negative & & .09 \\
Maternal Involvement (M) & -.14 & $-.14_{\mathrm{a}}$ & .19 & -.11 \\
Positive Parenting (M) & $-.08_{\mathrm{b}}$ & $.00_{\mathrm{c}}$ & -.05 & .34 \\
Family Routinization & $-.02_{\mathrm{d}}$ & -.07 & .31 & $-.66_{\mathrm{f}} * * *$ \\
YSR-Externalizing & -.10 & .10 & $-.51_{\mathrm{e}}^{* *}$ & \\
\hline
\end{tabular}

Note. SPOUSAL $=$ Child report of Spousal Role subscale of the Parentification Scale (PS); PARENTAL $=$ Child report of Parenting Role subscale of the PS; SIBLING = Child report of Parenting Siblings subscale of the PS; RESPONS. = Child report of Nonspecific Adult Responsibilities subscale of the PS; Maternal Involvement (M) = Mother report of involvement on Alabama Parenting Questionnaire (APQ); Pos. Parenting (M) = Mother report of positive parenting on APQ; Family Routinization = Mother report of family routines on Family Routines Inventory (FRI); YSR-Externalizing = Child report of externalizing behaviors on the Youth Self Report Form. Correlations with matching 
Table II (continued)

subscripts differ at $p<.05$ using Fisher $\mathrm{z}$ transformation to examine between-group differences in the strength and/or direction of the relationship between parentification variables and parenting and child adjustment variables.

$* p<.05 . \quad * * p<.01 . \quad * * * p<.001$. 